\title{
Effect of Intraluminal pH on the Absorption of Pteroylmonoglutamic Acid
}

\section{Summary}

British Medical fournal, 1971, 1, 148-150

The administration of pteroylmonoglutamic acid and either sodium bicarbonate or phenytoin sodium in normal subjects and epileptics results in lower serum levels of folic acid than when administered alone. Bicarbonate administration was shown to produce a more alkaline $\mathrm{pH}$ in the jejunum, while an alkaline pH was found in some epileptics on phenytoin therapy. The physicochemical mechanisms whereby folic acid absorption is reduced in an alkaline medium are considered, and the implications on folate absorption in other disease states are discussed. The mechanism by which phenytoin sodium alters the intrajejunal milieu is obscure.

\section{Introduction}

The association of megaloblastic anaemia with anticonvulsant therapy was first reported by Mannheimer et al. (1952). Since then low serum folate levels with macrocytosis have often been reported in patients on anticonvulsant therapy, notably primidone and phenylhydantoinates (Hawkins and Meynell, 1958; Klipstein, 1964). The mechanism by which folate metabolism is disturbed under these circumstances is uncertain. It has been suggested that competitive inhibition occurs at some stage in the folate metabolic pathway (Girdwood and Lenman, 1956; Newman and Sumner, 1957; Herbert and Zalusky, 1962). Dietary deficiency seems unlikely, since some of the patients have been well nourished (Hawkins and Meynell, 1958). Normal absorption has been found in most series with $5 \mathrm{mg}$ folic acid, but with much smaller doses impaired absorption has been claimed (Dahlke and MertensRoesler, 1962).

Pteroylmonoglutamic acid is a weak acid, so that alteration of $\mathrm{pH}$ could have a pronounced effect on the availability of any absorbable substance within certain ranges. The studies described here investigate the effect of phenytoin sodium and sodium bicarbonate on jejunal $\mathrm{pH}$ and on the absorption of synthetic pteroylmonoglutamic acid in vivo.

\section{Methods}

Folic Acid Absorption Studies.-Folic acid absorption curves were obtained by estimating the serum folate activity in the fasting state and at half, one, and two hours after an oral 5mg dose of folic acid, Lactobacillus casei being used as test organism (Herbert, 1966). Two male and three female

The General Hospital, Birmingham 4

ANN BENN. M.B., CH.B., Honorary Registrar in Gastroenterology C. H. J. SWAN, M.D., M.R.C.P., Honorary Senior Registrar in Gastroenterology

W. T. COOKE, M.D., F.R.C.P., Consultant Physician

University of Aston in Birmingham

J. A. BLAIR, PH.D., Senior Lecturer, Department of Chemistry A. J. MATTY, PH.D. Professor of Biological Sciences MARGARET E. SMITTH, PH.D., Research Fellow, Biological Sciences patients diagnosed as having idiopathic epilepsy and receiving phenytoin sodium for more than three years were studied. All were well nourished and taking an adequate diet, and at the time of investigation had normal blood counts and normal serum levels of vitamin $B_{12}$, folic acid, and iron. Fifteen normal subjects were investigated to establish the normal limits of the test of folic acid absorption, the results being compared with those obtained from the epileptic patients. Absorption tests were also carried out on the five epileptic patients and six volunteers (drawn from the control group of normal subjects) on two further occasions when either a single dose of $100 \mathrm{mg}$ phenytoin sodium or $10 \mathrm{~g}$ sodium bicarbonate was given simultaneously with $5 \mathrm{mg}$ folic acid orally. In one volunteer sodium bicarbonate induced colic and diarrhoea; the results obtained were not included in the mean absorption curve for this group. None of the epileptics took their regular anticonvulsant on the day of investigation. Absorption curves were also obtained from a normal subject after the simultaneous administration of $5 \mathrm{mg}$ folic acid and $10 \mathrm{~g}$ sodium bicarbonate, or Garoin (phenytoin $100 \mathrm{mg}+$ phenobarbitone $50 \mathrm{mg}$ ), and after administration of Garoin three times a day for 10 days.

Human Intraluminal pH Studies.-The Cambridge combined glass/calomel electrode was used with a Pye $\mathrm{pH}$ meter and Duplex chart recording system to provide permanent records of the traces of intraluminal conditions of the duodenum and upper jejunum (Benn and Cooke, 1970). The intestinal intraluminal $\mathrm{pH}$ of the five patients on long-term treatment with phenytoin sodium, including three who had had megaloblastic anaemia, was determined at various sites. In addition, the intestinal intraluminal $\mathrm{pH}$ of two volunteers was studied before and during the administration of $10 \mathrm{~g}$ sodium bicarbonate orally. In all cases the intestinal $\mathrm{pH}$ studies were conducted after an overnight fast, and none of the epileptics received anticonvulsants on the day of investigation.

\section{Results}

Folic Acid Absorption Studies. - The results obtained in the folic acid absorption studies are shown in Fig. 1. The range obtained in 15 normal control subjects is depicted, on which is superimposed the mean level for that range. Impairment of folate absorption occurred in normal controls when $5 \mathrm{mg}$ folic acid was administered simultaneously with $10 \mathrm{~g}$ sodium bicarbonate. In the epileptic group impaired absorption of folic acid below the range of the control group was observed, and this effect was unchanged by the administration of $5 \mathrm{mg}$ folic acid with $10 \mathrm{~g}$ sodium bicarbonate. In the normal subject pronounced impairment of folate absorption was observed at the end of the 10-day course of anticonvulsant therapy. A similar effect was observed with the simultaneous administration of either $10 \mathrm{~g}$ sodium bicarbonate or $100 \mathrm{mg}$ Garoin with the oral dose of folic acid (Fig. 2).

Intraluminal $\mathrm{pH}$ Studies. - The intestinal intraluminal $\mathrm{pH}$ studies in five epileptics on long-term anticonvulsants is compared with the range normally encountered in control subjects in Fig. 3. The three patients with the most alkaline intraluminal $\mathrm{pH}$ had had folic-acid-deficient megaloblastic anaemia previously. The jejunal intraluminal $\mathrm{pH}$ traces 


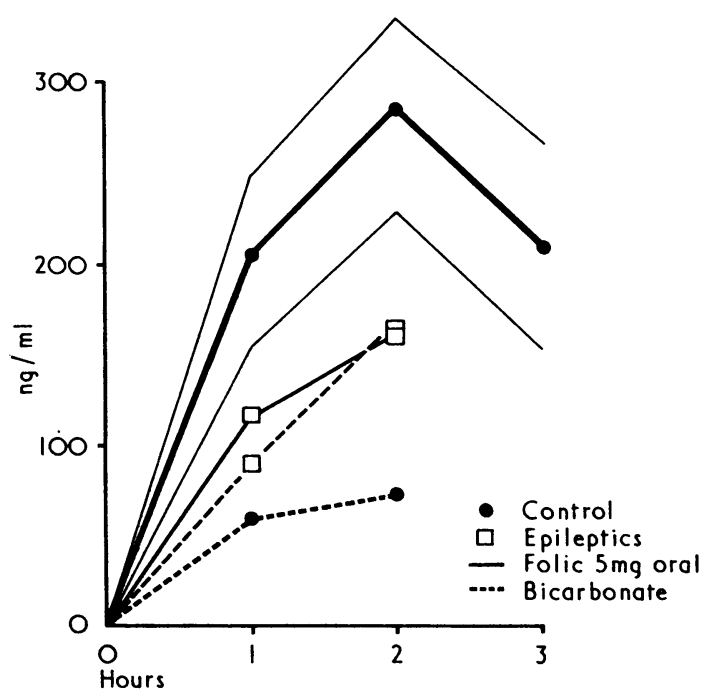

FIG. 1-Mean and range of levels of serum folic acid (L.casei) after adminisFIG. 1-Mean and range of levels of serum folic acid (L.casei) after adminis(closed circles' represents the mean serum folic of five normal subjects after $5 \mathrm{mg}$ folic acid $+10 \mathrm{~g}$ sodium bicarbonate. The solid line (open squares) represents the control findings in five epileptics on long-term anticonvulsant therapy after $5 \mathrm{mg}$ folic acid. The dotted line (open squares) represent the serum levels when folic acid was administered with $10 \mathrm{~g}$ sodium bicarbonate to the five epileptics.

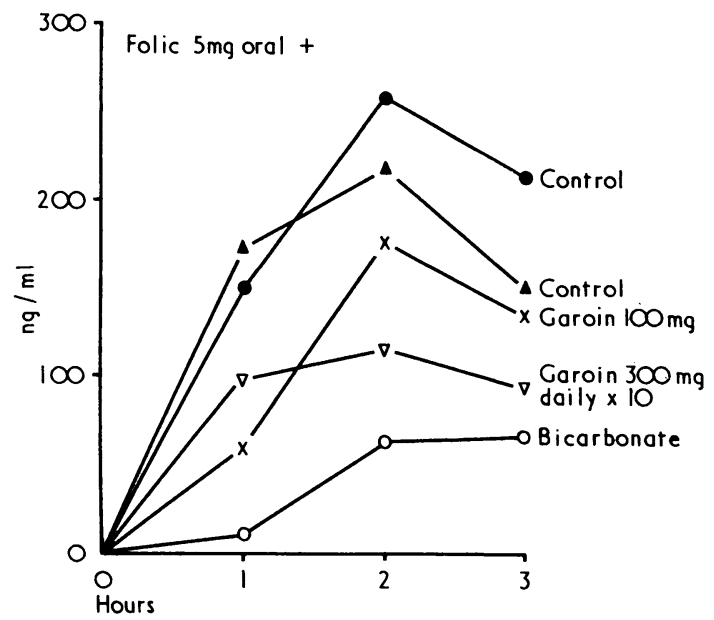

FIG. 2-Serum folic levels in a normal subject after $5 \mathrm{mg}$ folic acid (closed circles), $5 \mathrm{mg}$ folic acid and $10 \mathrm{~g}$ bicarbonate (open circles), $5 \mathrm{mg}$ folic + Garoin $100 \mathrm{mg}$ (open squares), and $5 \mathrm{mg}$ folic acid after $300 \mathrm{mg}$ Garoin daily for 10 days (crosses).

obtained in two normal volunteers after the administration of doses of $10 \mathrm{~g}$ sodium bicarbonate are shown in Fig. 4. In both of them sodium bicarbonate produced protracted alkalinization of the jejunal contents, and return to normal intraluminal $\mathrm{pH}$ was delayed.

\section{Discussion}

The site of optimal absorption has been established as the proximal jejunum both in rats (Burgen and Goldberg, 1962; Herbert and Shapiro, 1962; Yoshino, 1968) and in man (Chanarin et al., 1958; Cox et al., 1958; Chanarin and Bennett, 1962). Different workers have produced evidence in favour of active transport (Burgen and Goldberg, 1962; Herbert, 1967; Hepner et al., 1968) and passive diffusion (Turner and Hughes, 1962; Spencer and Bow, 1964; Yoshino, 1968). It has been suggested that both mechanisms exist at different levels of the small bowel in the rat (Hepner, 1969). The absorption of folic acid is a complex phenomenon affected by

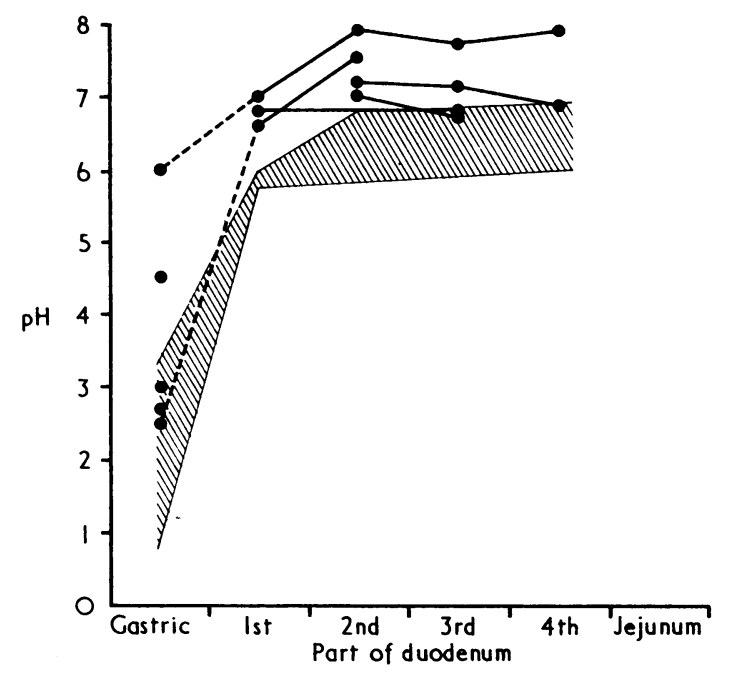

FIG. 3-Shaded area covers the range of $\mathrm{pH}$ encountered in normal subjects. The points represent the intraluminal $\mathrm{pH}$ in five epileptic patients on longterm anticonvulsant therapy. Each point was taken at a time when tracin was constant for at least seven minutes. The three with the most alkaline pH had had a folic-acid-deficient megaloblastic anaemia.

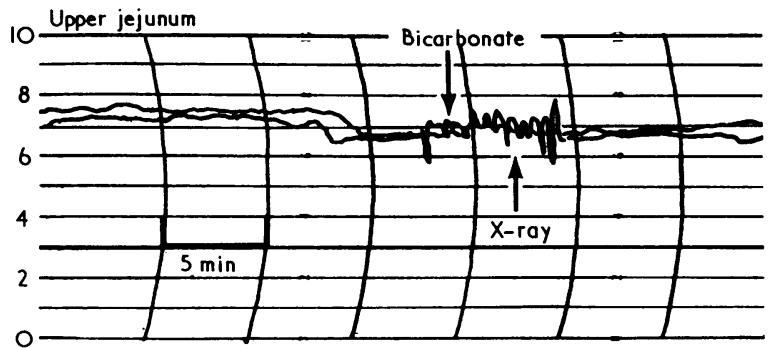

FIG. 4-Intrajejunal pH tracings of two normal subjects. The break in tracings represents the point at which radiological verification of the position of the electrode was obtained, following which $10 \mathrm{~g}$ sodium bicarbonate was administered.

dissociation at varying $\mathrm{pH}$, water transport, ionic flux, glucose transport, and solvent drag (Smith et al., 1970a, 1970b), but since previous experimental work failed to control these factors many of the conclusions are questionable.

Pteroylmonoglutamic acid is weakly acidic and exists in solution as the neutral compound, monanion, dianion, and trianion, the relative amounts of which vary with the $\mathrm{pH}$ of the solution. It is extremely important, therefore, to consider which forms are concerned in any transport mechanism, and what effect the ambient pH may have on dissociation (Matty and Blair, 1968). Studies on the transport of weakly acidic drugs across the rat intestinal wall suggest that only the neutral acid is transported and that this form is transported through the lipoid barrier (Pohland et al., 1951; Schanker et al., 1958; Hogben et al., 1959). Furthermore, these studies showed that zones of greater acidity than that of intestinal chyme exist at the mucosal interface of the rat intestine. Such zones, or "microclimates," have a virtual pH of 5.3 in the rat when the bathing solution is at pH 7.4 (Schanker et al., 1958), but the mechanism whereby these are procured are as yet obscure. Matty and Blair (1968) suggested that folic acid should be transported as the neutral compound across the lipoid barrier. At pH 5.0 only about $1 \%$ folic acid in aqueous solution is present in the neutral form, and with increasing alkalinity, even less. Therefore, any absorptive processes will be limited by conditions which exist within the microclimate which in its turn will be influenced by mucosal or intraluminal conditions.

Various mechanisms have been proposed to explain the impairment of metabolism of pteroylmonoglutamic acid by phenytoin. It was proposed that intestinal conjugase activity 
was impaired by the anticonvulsant (Hoffbrand and Necheles, 1968; Rosenberg et al., 1968), but though conjugase activity was definitely impaired by phenytoin sodium in vitro, the study was not performed at the normal intraluminal $\mathrm{pH}$ of the jejunum. Furthermore, impairment of conjugase activity should have no effect on the absorption of pteroylmonoglutamic acid. More recently, phenytoin has been shown to have no effect on conjugase activity with a pure $\mathrm{C}^{14}$-labelled triglutamate (Baugh and Krumdieck, 1969). It has been claimed that the conjugase system is of minor significance since all diets when assayed in the presence of ascorbate contain adequate amounts of monoglutamate to satisfy daily body requirements (Hurdle et al., 1968). It is probable, therefore, that some other mechanism exists whereby phenytoin inhibits the absorption of monoglutamate.

Though it has been suggested that intraluminal $\mathrm{pH}$ changes may be of importance (Butterworth, 1968), the role of intraluminal and juxtamucosal $\mathrm{pH}$ in folic acid absorption has received little attention. Studies described here emphasize the effect that such changes may have on the absorption of pteroylmonoglutamic acid for the intraluminal $\mathrm{pH}$ of a group of epileptics treated with oral phenytoin sodium were more alkaline. Under these circumstances less pteroylmonoglutamic acid would be in a form suitable for absorption.

Proprietary preparations of phenytoin (Epanutin) in solution have a $\mathrm{pH}$ in the region of 12.0 ; sodium bicarbonate solution has a $\mathrm{pH}$ of 8.0 . In our experience the effect of phenytoin sodium on pteroylmonoglutamate absorption was mimicked by the oral administration of sodium bicarbonate, and similar alterations in intraluminal $\mathrm{pH}$ were produced in two normal subjects. In clinical situations such alterations in the jejunum may be a significant factor in folate malabsorption. For example, in adult coeliac disease, where folate malabsorption often occurs, some untreated patients have an intraluminal jejunal $\mathrm{pH}$ between $\mathrm{pH} 7.5$ and 8.5 (Benn and Cooke, 1970) so that dietary monoglutamate absorption is impaired sufficiently to precipitate folate deficiency.

In conclusion, evidence presented in our study suggests that changes in the bulk phase of intraluminal $\mathrm{pH}$ may have a profound effect on the absorption of pteroylmonoglutamic acid in epileptics and in normal subjects.
We wish to thank Dr. M. J. Meynell, consultant haematologist, United Birmingham Hospitals, for his help and advice and the Medical Research Council for financial support of two of us (A.B. and M.E.S.).

\section{References}

Baugh, C. M., and Krumdieck, C. L. (1969). Lancet, 2, 519.

Benn, A., and Cooke, W. T. (1970). Scandinavian fournal of Gastroenterology.

In press.
Burgen, A. S. V., and Goldberg, N. J. (1962). British fournal of Pharmacology and Chemotherapy, 19, 313 .

Butterworth, C. E., jun. (1968). British fournal of Haematology, 14, 339.

Chanarin, I., Anderson, B. B., and Mollin, D. L. (1958). British fournal of Haematology, 4, 156.

Chanarin, I., and Bennett, M. C. (1962). British Medical fournal, 1, 985.

Cox, E. V., Meynell, M. J., Cooke, W. T., and Gaddie, R. (1958). Gastroenterology, 35, 390.

Dahlke, M. B., and Mertens-Roesler, E. (1967). Blood, 30, 341

Girdwood, R. H., and Lenman, J. A. R. (1956). British Medical fournal, 1, 146.

Hawkins, C. F., and Meynell, M. J. (1958). Quarterly fournal of Medicime, 27,45 .

Hepner, G. W. (1969). British fournal of Haematology, 16, 241.

Hepner, G. W., Booth, C. C., Cowan, J., Hoffbrand, A. V., and Mollin, D. L. (1968). Lancet, 2, 302 .

Herbert, V. (1966). Fournal of Clinical Pathology, 19, 12.

Herbert, V. (1966). Fournal of Clinical Pathology, 19, 12.

Herbert, V. (1967). American fournal of Clinical Nutrition, 20, 562.

Herbert, V., and Shapiro, S. S. (1962). Federation Proceedings, 21, 260. 1263 .

Hoffbrand, A. V., and Necheles, T. F. (1968). Lancet, 2, 528.

Hogben, C. A. M., Tocco, D. J., Brodie, B. B., and Schanker, L. S. (1959) fournal of Pharmacology and Experimental Therapeutics, 125, 275.

Hurdle, A. D. F., Barton, D., and Searles, I. H. (1968). American fourna of Clinical Nutrition, 21, 1702 .

Klipstein, F. A. (1964). Blood, 23, 68

Mannheimer, E., Pakesch, F., Reimer, E. E., and Vetter, H. (1952). Medizinische Klinik, 47, 1397.

Matty, A. J., and Blair, J. A. (1968). Lancet, 2, 978.

Newman, M. J. D., and Sumner, W. D. (1957). Blood, 12, 183

Pohland, A., Flynn, E. H., Jones, R. G., and Shive, W. (1951). Fournal of the American Chemical Society, 73, 3247.

Rosenberg, I. H., Godwin, H. A., Streiff, R. R., and Castle, W. B. (1968). Lancet, 2,530 .

Schanker, L. S., Tocco, D. J., Brodie, B. B., and Hogben, C. A. M. (1958) fournal of Pharmacology and Experimental Therapeutics, 81, 123.

Smith, M. E., Matty, A. J., and Blair, J. A. (1970a). Gut, 11, 368.1 Smith, M. E., Matty, A. J., and Blair, J. A. (1970b). Biochimica et Biophysica Acta. 219, 37.

Spencer, R. P., and Bow, T. M. (1964). Fournal of Nuclear Medicine, 5, 251

Turner, J. B., and Hughes, D. E. (1962). Quarterly Journal of Experimento Physiology, 47, 107 .

Yoshino, T. (1968). fournal of Vitaminology, 14, 21. 